\section{RIGOR E APRENDIZADO COM AS GEOGRAFIAS FEMINISTAS E DAS SEXUALIDADES}

Stephanie Ares Maldonado

SILVA, Joseli Maria; ORNAT, Marcio José; CHIMIN JR., Alidades Baptista (Orgs.). Geografias feministas e das sexualidades: encontros e diferenças. Ponta Grossa: Todapalavra, 2016.

ISBN: 978-85-62450-47-1

A busca por entender as relações sociais, culturais e políticas entre pessoas "distintas" não é assunto novo na história das ciências humanas e sociais - mesmo que possamos reconhecer que, em parcela desses estudos, alguns grupos sociais podem ter sido pouco (menos que o necessário) ou insensivelmente trabalhados (que é o caso da mulher, por exemplo). Por isso, é necessário ressaltar a empatia presente no modo como foram tratados grupos pouco privilegiados nesta "coletânea de textos anglófonos traduzidos para o português" que é o "Geografias feministas e das sexualidades: encontros e diferenças".

Como já diria Miguel Angelo Ribeiro, no prefácio ("Geografias malditas, malditas geografias?: a discussão de gênero e sexualidades no mundo, segundo diferentes pontos de vista"), o livro "traz uma importante contribuição para transformar a discriminação em trono de gênero e sexualidades a partir do espaço" (p.10). Concretizado em 2016, foi um brinde e um empreendimento oportuno do Grupo de Estudos Territoriais (Gete), instaurado em Ponta Grossa (PR), em um cenário que ainda exigia prestígio da produção nacional sobre a temática e, ao mesmo tempo, ampliação do nosso conhecimento sobre abordagens estrangeiras antecedentes (p.9).

Desde 2003, o grupo vem pesquisando "temáticas que fogem às normas vigentes", em um assumido propósito político igualmente dedicado à rigorosidade científica. Esse esforço se vê expresso no primeiro texto do livro, único de origem brasileira, intitulado "Sobre as desobediências epistemológicas e o testamento intelectual de Milton Santos" e escrito pelos organizadores do livro: Joseli Maria Sila (coordenadora do Gete) e dois de seus colegas de grupo, Marcio Jose Ornat e Alides Baptista Chimin Junior (p.9). A intenção se encontra em "produzir uma geografia brasileira

1 Mestranda no Programa Interdisciplinar em Ciências Humanas e Sociais Aplicadas, Faculdade de Ciências Aplicadas da Unicamp. stephanie118691@gmail.com.

$\bowtie$ Caixa Postal 1068, Limeira, SP. 13484-350.

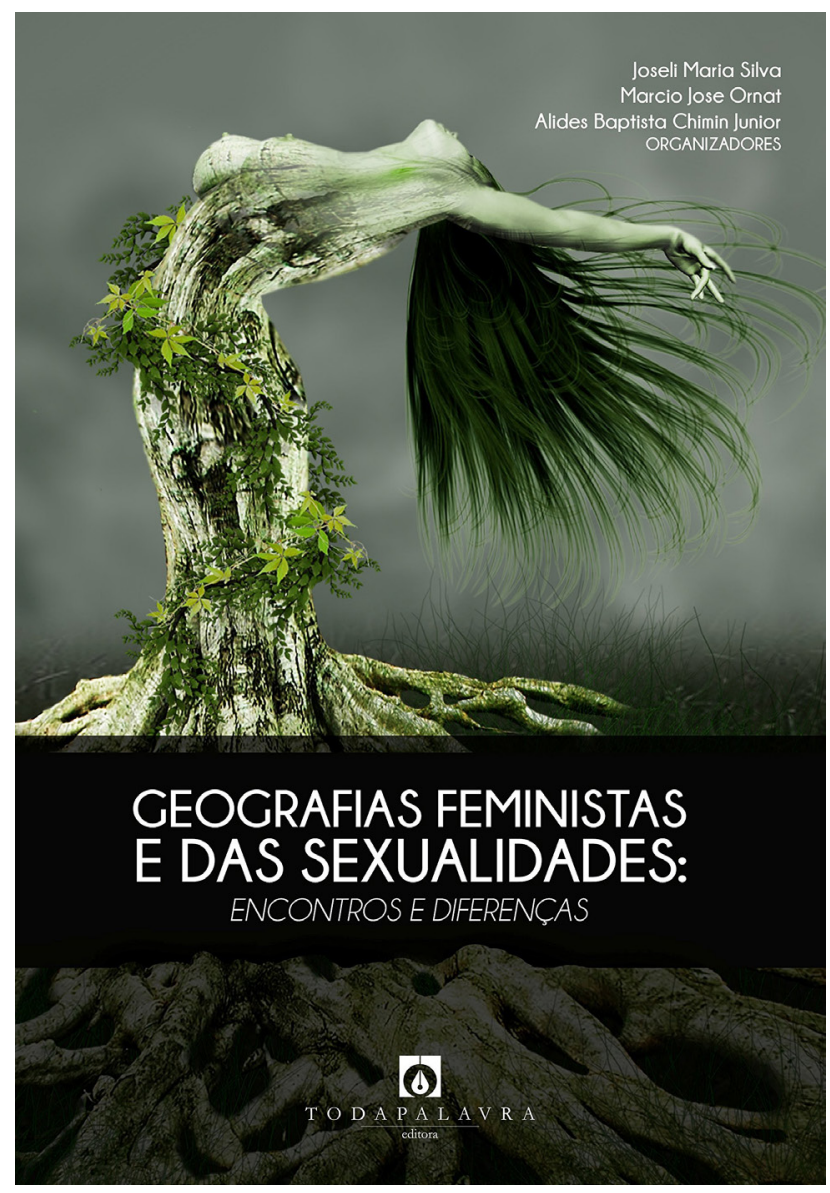

capaz de trazer sujeitos generificados, sexualizados e racializados para o centro do debate científico" (p.12).

Argumenta-se que esses "sujeitos" têm sido negligenciados nos debates científicos, tornando necessário um aprimoramento do modo de pesquisa, rumo à afirmação dessas existências espaciais diversas - existências que muitas vezes desafiam "nossa própria tradição epistemológica". 
Nesse contexto que aparece Milton Santos: intelectual brasileiro que contribuiu significativamente ao entendimento dos alcances e limites conceituais (p.15-20), deixando caminhos abertos para serem desbravados por novas geografias.

Por sua vez, os legados deixados pelos mestres, como Milton Santos, não devem limitar as novas geografias. Além de preencher lacunas deixadas anteriormente, elas podem se distanciar rumo a outras abrangências. Por exemplo, as geografias feministas que decidiram suprimir certos legados rumo à corporificação dos agentes geográficos (p.26).

Ao menos para circunscrever melhor o escopo de suas próprias metodologias, é indispensável que os pesquisadores brasileiros conheçam as contribuições das geografias feministas. No mínimo, que se familiarizem com aquelas pioneiras que marcaram o campo da geografia, como os nove textos anglo-saxões trazidos pelo livro em foco. Ainda que o debate possa estar sob possíveis "relações de poder que ainda permeiam as relações intelectuais entre o norte e o sul" que devem ser problematizadas (p.28), são pesquisas que merecem uma certa dedicação. Principalmente, por terem abalado os alicerces de toda uma disciplina, servindo de orientação e inspiração até os dias atuais, inclusive no Brasil.

"Não excluam metade da humanidade da geografia humana" (de Janice Monk e Susan Hanson) é um desses casos icônicos. O texto buscou afirmar o aperfeiçoamento científico que uma geografia feminista pode proporcionar, dando a esse elemento o mesmo peso que, normalmente, se dão aos esperados efeitos políticos. Para as autoras, as experiências femininas foram deixadas de lado na geografia humana (mais ainda do que em outras ciências) por demasiado tempo, causando prejuízos para se compreender "comunidades" para além das "generalizações" oriundas "unicamente a partir de dados sobre os homens" (p.31, 38).

Geograficidade | v.8, Número 2, Inverno 2018 ISSN 2238-0205
A "cegueira de gênero" ocultou aspectos da realidade e empobreceu diversas conclusões científicas, apontando para a indispensabilidade de se levar em consideração "a diversidade das experiências e necessidades das mulheres". Para além da "retificação de estereótipos e a superação de omissões", como se preocuparam os primeiros estudos feministas, uma "coleta de dados", na disciplina geográfica, "a partir de indivíduos (ou de combinações apropriadamente variadas de indivíduos) ajudaria a evitar esse viés masculino". Isso poderia resultar, por exemplo, em políticas públicas mais pertinentes para realidades espaciais singulares (p.34-47).

Por outro lado, uma ampliação da perspectiva feminista na geografia auxilia igualmente a uma compreensão mais adequada da própria masculinidade e das experiências dos homens, como mostra o artigo "Masculinidade, dualidades e alta tecnologia" de Doreen Massey. A própria racionalidade (e "lógica") que se enraizou na ciência durante décadas criou e perpetuou dualidades (como "razão/desrazão e transcendência/imanência") e tensões (entre "esferas" da "'casa e do trabalho'"), que uma perspectiva feminista é capaz de desmontar (p.55-61).

Doreen Massey expôs uma variedade de motivos para as "longas jornadas de trabalho" (p.58), implicações do "fenômeno Cambrige", para a vida (privada e profissional) de homens ingleses pesquisadores e criadores "de novos produtos" (p.56) - e o impacto disso para as mulheres que são envolvidas com esses homens, principalmente esposas.

As conclusões são surpreendentes, pois mostra como "a longeva dualidade ocidental" aprisionou a masculinidade, sua própria criadora. Sendo assim, a coerente proposta da autora para romper com a problemática apreendida é justamente romper com a "estrutura dualista" que a proporcionou (p.78-79). 
O terceiro texto traduzido, "Desenvolvimento rural em El Hatillo, Nicarágua: gênero, neoliberalismo e risco ambiental" de Julie Cupples, acaba também por trabalhar a masculinidade. Mas, digamos, com o foco invertido. Nessa investigação, evidencia-se a resiliência e a importância das mulheres locais frente aos desastres ambientais em El Hatillo, especialmente depois do "furacão Mitch" de 1999 (p.8384) - tangenciando a questão masculina no que concerne ao impacto sentido com essa mobilização feminina.

Interseccionada entre as consequências do "neoliberalismo", da "pobreza" e da "degradação ambiental", El Hatillo dependeu da força de trabalho e organização feminina para se (re)estruturar após o desastre. Essa particularidade resultou em alguns maiores sucessos de recuperação em comparação àqueles obtidos por outros lugares nicaraguenses atingidos pelo furacão. $O$ que essas mulheres criaram ou sacrificaram em prol de toda a "comunidade" começou a alterar positivamente as "subjetividades de gênero" locais, ou seja, as relações intersubjetivas entre esses homens e mulheres. Por outro lado, também escancarou ambiguidades que circundaram o processo de "libertação" feminina (p.89-99). O trabalho de Julie Cupples é uma amostra precisa da contribuição das geografias feministas para o "conhecimento geográfico" - e os motivos para essa afirmação podemos entender a partir da análise feita por Peter E. Hopkins, no capítulo que se segue.

Em "Mulheres, homens, posicionalidades e emoções: fazendo geografia feministas da religião", o autor indica três (de algumas) das contribuições feministas na geografia: a "compreensão das maneiras como as mulheres experienciam o espaço", "o desenvolvimento das perspectivas que tomam a natureza do conhecimento geográfico como saber localizado" e "a construção da crítica do caráter sexista e excludente da sociedade" (p.108).

Preocupado em alargar a esfera de estudos sobre "geografias feministas da religião" (e buscando apontar possibilidades de pesquisas

Geograficidade | v.8, Número 2, Inverno 2018

ISSN 2238-0205 futuras com esse mesmo propósito), o autor traz uma multiplicidade de pensamentos feministas e experiências "de campo" para mostrar como "jovens mulçumanos" viventes no Reino Unido apreendem e constituem sua própria masculinidade. Muitas vezes, forçando-a contra aquilo que entendem por feminilidade (p.108-113).

Estes embates entre masculinidade e feminilidade (por uma perspectiva corporal) também perpassou o texto "Uma perfeita geezer-bird (mulher-homem): os lugares e olhares de corporalização 'feminina'" de Kath Browne. O artigo discorre sobre as experiências de "nove mulheres que são confundidas com homens", as violências e incongruências sobre esse fenômeno (p.131).

A autora criticou ativamente "teorias queer" que confundem certas discriminações de gênero com discriminações de sexualidade, assim como feminismos que incompreendem as experiências de "lésbicas 'masculinizadas'" por criarem separações rígidas e irreais entre gênero e sexualidade (p.132-148).

Lynda Jhonston, em "I do down-under': naturalizando paisagens e amor através do turismo matrimonial na Nova Zelândia", também articulou "geografias de gênero" com "teorias queer", como fizera Browne (p.152) - e ainda incorporou no debate o elemento racial. A sustentação de seus argumentos por essa tríade foi importante, porque fez entender como os casamentos e "paisagens" vendidos pelo "turismo matrimonial" da Nova Zelândia ajudam a sustentar a moralidade e aceitabilidade do casamento heterossexual, enquadrando-o em um ideário "'puro'" e "'natural'" e perpetuando um imagético que menospreza a figura asiática - mesmo que a maior parte desses turistas sejam de origem japonesa (p.158-164).

As pesquisas presentes no livro "Geografias feministas e das sexualidades" mostram que certos grupos de indivíduo são socialmente discriminados por fatores que, muitas vezes, são fluidos 
e se entrelaçam: como sexo, gênero, classe social, raça ou origem. Gavin Brown reafirma essa linha de pensamento em "O casamento e o quarto de hóspedes: explorando a política sexual de austeridade na Grã-Bretanha". O autor desvela como, sob novos discursos normativos, "outras formas de relacionamento, intimidade e modos de vida" são colocadas sob "um escrutínio renovado" (p.189).

Suas observações partem dos "núcleos familiares de baixa renda", heterossexuais e homossexuais, que sofrem com as "reformas drásticas e punitivas dos serviços de previdência" relativamente novos da Grã-Bretanha (SLATER apud BROWN, 2016, p.190). Reformas que são sustentadas por discursos neoliberais específicos que conformam "padrões" e "novas formas de disciplina" (p.193).

Toronto, uma cidade que costuma se apresentar como aberta à "diversidade", demonstra em sua realidade também privilegiar certas tipologias sociais em detrimento de outras. Quando analisado a constituição de "espaços de HIV/AIDS na cidade de Toronto", percebe-se que ela padece de uma "cegueira racial" ligada ao liberalismo, que prejudica diferentemente ("imigrantes") asiáticos e negros (homossexuais e heterossexuais) no acesso a serviços de "saúde sexual" - o que acaba por solicitar novos "refúgios" e tipos de resistência. Foi isso que mostrou John Paul Catungal no texto "Refúgios etnoespecíficos na zona de contato liberal: política racial, construção de espaço e as genealogias do setor de AIDS na cidade multicultural global de Toronto" (p.197-210).

Por fim, o último capítulo da coletânea revela a perspicácia dos organizadores do livro. Não só na escolha dos textos, mas também na ordem de leitura proposta, que incorpora narrativas cada vez mais complexas. Isso não quer dizer que aqueles iniciais não eram profundos o suficiente. Todavia, textos como de Cesare Di Feliciantonio, "A política sexual do neoliberalismo e a austeridade num país 'excepcional': a Itália", exigem uma certa familiaridade com o tema central familiaridade que o próprio livro vai nos fornecendo em seu decorrer.

No desenrolar de sua avaliação, o autor se utiliza da "teoria da 'exceção"' (p.259) para desmontar a ideia de "homonormatividade". Seguindo o raciocínio, critica o senso comum de "neoliberalismo", fazendo um movimento contrário, onde o conceito se enche de elementos múltiplos e não lineares. Di Feliciantonio mostra como, ao invés do que uma visão simplista e uniforme sugere, o próprio ambiente neoliberal acaba solicitando "novas exceções" na "política sexual" italiana (p.259).

São cognoscíveis os pontos de afastamento e de aproximação entre os autores sobre temas como (neo)liberalismo, ciência e opressão. Em Di Feliciantonio, talvez isso se evidencie através da clareza de concordância ou discordância com que ele se posiciona. No entanto, está aí a preciosidade do livro. Entre discursos mais acessíveis e outros nem tanto, "Geografias feministas e das sexualidades" traz reverberações preciosas para as discussões de gênero e sexualidade e para o campo dos estudos culturais e humanistas na geografia.

Evidenciou-se que uma perspectiva geográfica e feminista pode colaborar no entendimento das conformações identitárias em diferentes contextos. O espaço, que tanto faltou aos estudos de gênero e sexualidade, é capaz de pôr a vista qualidades e particularidades pouco perceptíveis em um panorama cultural e social generalizado.

Por exemplo, "os contornos racializados do campo da saúde sexual na Toronto da década de 80" (p.227) se evidenciaram em razão da questão espacial compor o estudo. Afinal, era comum relacionar o assunto apenas a "sexualidade e suas políticas" (p.206). Por outro lado, os relativamente tardios questionamentos feministas dentro do campo da geografia agregam tanto em uma "coleta de dados" mais precisa em relação à realidade (p.46), quanto na criação de epistemologias e 
metodologias capazes de visibilizar e combater as organizações sociais patriarcais e as desigualdades que nelas se perpetuam (p.40).

Contudo, a contribuição do livro não se encerra nessas discussões, da mesma maneira que não se faz exclusivamente para estudiosos feministas. Isto porquê levar em consideração questões corporais e espaciais de gênero e sexualidade pode auxiliar pesquisadores de outras abordagens em questões basais, como no enfrentamento do mito do pesquisador neutro (p.16).

Assumir-se na pesquisa, concomitantemente com assumir a subjetividade do outro, pode ajudar a transformar aquilo que sempre foi visto como um "defeito" das ciências humanas e sociais em uma potencialidade, como fazem as "geografias emocionais" das quais falava Hopkins (p.119).

De qualquer modo, as geografias aqui apresentadas abrem possibilidades de pesquisas futuras, onde cabe a nós escolhermos quais abarcar e quais recusar - portanto que cessemos de ignorar essas experiências outras que, finalmente, saem do olhar periférico da academia para verem a si próprias emergirem ao centro, na possibilidade (não mais remota) de serem espacialmente e corporalmente validadas. () 